\title{
Does fortification of more foods with vitamin D improve vitamin D intakes and status of groups at risk of deficiency in the UK?
}

\author{
R. E. Allen ${ }^{1 *}$ A. D. Dangour ${ }^{2}$, Z. Chalabi $^{2}$ and A. Tedstone ${ }^{1}$ \\ ${ }^{1}$ Public Health England, Wellington House, London, SE1 $8 U G$ and ${ }^{2}$ London School of Hygiene and Tropical Medicine, \\ Keppel Street, London, WC1E $7 H T$
}

Parts of the UK population have poor vitamin D status, particularly those with low sun exposure and/or poor dietary intake. This study aimed to identify possible fortification vehicle(s) and level(s) most likely to increase population vitamin D intakes above minimum reference thresholds for intake and status without exceeding maximum reference thresholds.

UK food consumption data from the first two years (2008-10) of the National Diet and Nutrition Survey (NDNS) Rolling Programme ${ }^{(1)}$ were manipulated to simulate the effect of fortifying wheat flour and milk-containing products with vitamin D at a range of levels between $2.5 \mu \mathrm{g}$ and $30 \mu \mathrm{g}$ vitamin D per $100 \mathrm{~g}$ flour; and $0.25 \mu \mathrm{g}$ and $7 \mu \mathrm{g}$ vitamin D per $100 \mathrm{ml}$ milk. Empirically derived equations $^{(2,3)}$ for the relationship between vitamin $\mathrm{D}$ intake and winter serum 25-hydroxyvitamin D [25(OH)D] levels were used to determine population winter serum $25(\mathrm{OH}) \mathrm{D}$ levels for each fortification scenario.

At a simulated fortification level of $10 \mu \mathrm{g}$ vitamin D per $100 \mathrm{~g}$ wheat flour, the proportion of 'at risk' groups estimated to have vitamin D intakes below the UK Reference Nutrient Intake (RNI) ${ }^{(4)}$ was reduced from $93 \%$ to $50 \%$, with no individual exceeding the European Tolerable Upper Intake Level $(\mathrm{UL})^{(5)}$ for vitamin D and the $2 \cdot 5^{\text {th }}$ percentile of population winter serum $25(\mathrm{OH}) \mathrm{D}$ levels rose from $20 \mathrm{nmol} / 1$ to $27 \mathrm{nmol} / \mathrm{l}$ post fortification, above the UK minimum reference threshold of $25 \mathrm{nmol} / \mathrm{l}$. Simulation of fortification of wheat flour at this level improved intakes across all socio-economic groups and was found to be more effective than fortification of milk, and simultaneous fortification of milk and flour.

This study provides new evidence that vitamin $\mathrm{D}$ fortification of a staple food such as wheat flour in the UK could be a viable option for improving vitamin D intakes and status of population groups at risk of deficiency without increasing the risk of exceeding current reference thresholds.

1. National Centre for Social Research MRC. (2012) National Diet and Nutrition Survey, 2008-2010 [computer file]. 3rd Edition. SN: 6533. Resource Centre for Human Nutrition Research and University College London. Medical School, Colchester, Essex UK Data Archive [distributor] February 2012; Available from: http://dx.doi.org/10.5255/UKDA-SN-6533-2

2. Cashman KD, Hill TR, Lucey AJ, et al. (2008) Estimation of the dietary requirement for vitamin D in healthy adults. Am J Clin Nutr 88, 1535-42.

3. Cashman KD, Wallace JMW, Horigan G, et al. (2009) Estimation of the dietary requirement for vitamin D in free-living adults $\geq 64$ y of age. Am $J$ Clin Nutr 89, 1366-74

4. Department of Health. (1991) Dietary Reference Values for Food Energy and Nutrients for the United Kingdom. Report on health and social subjects, 41. London: HMSO.

5. European Scientific Committee on Food. (2002) Opinion of the Scientific Committee on Food on the Tolerable Upper Intake Level of Vitamin D. [17.02.14]; Available from: http://ec.europa.eu/food/fs/sc/scf/out157_en.pdf. 